\title{
Midwife's experiences of using intuition as a motivating element in conveying assurance and care
}

\author{
Agneta Olsson, Annsofie Adolfsson
}

School of Life Sciences, University of Skövde, Skövde, Sweden; *Corresponding Author: Annsofie.adolfsson@his.se

Received 14 April 2011; revised 30 May 2011; accepted 11 June 2011.

\section{ABSTRACT}

The expectations of a successful outcome during childbirth are high for all of the parties concerned. The overall objective of prenatal care and birth care is that midwives contribute to create the most positive experience for the expectant parents concerning their pregnancy, the actual childbirth and the child's infancy. During the past thirty years, there has been a significant increase in Caesarean section frequency both in Sweden and in the rest of the Western World. More parents feel an overall insecurity when it comes to the labor phase leading up to childbirth. The purpose of this study was to describe how midwives experience their work of creating a sense of security and providing good nursing care when meeting with the expectant parents. A phenomenological approach was implemented using eleven qualitative interviews and these were analyzed with Giorgis' method of analysis. The results of this analysis revealed three themes: organizational-professional conditions, the communicative ability of the midwives and their reflective-emotional competence. The ability of the midwives to trust their inner sensibility and intuition was something that was characteristic of all the interviews and consequently this was the essence of the results. Managements' organization of the workload and how management utilized competent and experienced midwives affected the midwives' ability to contribute to a sense of security and provide competent nursing care for expectant parents. When the communication was based on sensibility and compassion, the midwives' were enabled to create a sound and trusting relationship between themselves, the MVC and with the expectant parents. The emotional involvement on the part of the midwives was an essential requirement for carrying out the work in a satisfactory manner. Perhaps a question for future research is how inner knowledge based on practical experience can benefit new personnel and how the organization and the education of healthcare providers can utilize the intuitive knowledge of midwives.

Keywords: Fear of Childbirth; Midwife Encounter; Support Midwife; Security in Childbirth

\section{INTRODUCTION}

This study is about using the experience of midwives to contribute and provide proper nursing care for expectant mothers by helping them to develop a sense of security with consistent and competent care for the women during their pregnancy and through the delivery of the baby. The expectations for a successful delivery are high for all concerned. Therefore, the demands are high within the Maternity Health Care system (MVC) and the delivery ward to offer the expectant parents the best care possible [1]. The healthcare in Sweden for pregnant women is managed from a national base program with guidelines to identify possible complications and their reasons. The role of the midwife is to contribute to a meaningful and positive experience of the pregnancy, delivery of the baby and the infancy.

The professional role of the midwife has changed during the last couple of decades. Healthcare today for pregnancy and child delivery has a large focus on the symptoms of possible psychological issues and dysfunction which are often due to fears associated with pregnancy, the delivery and even child raising. Pregnancy and delivery healthcare has become more of a medical matter since women have moved from delivering babies at the home, to the delivering their babies in the hospital. As a result, the care is focused on the complications, the risks and the outcome of the delivery than it is on the women's experiences of the pregnancy and the delivery [2].

In the last thirty years, the number of Caesarean section deliveries has increased in Sweden from approxi- 
mately six percent to nineteen percent and the percentage is slightly higher in the larger cities. This phenomenon is not unique for Sweden when compared with the rest of the Western World [3].

When the author of this study began working as a midwife, the birthrate in Sweden was high and consequently the workload for midwives was high. The final training for a midwife student at the time was to manage the care of two or three women who were in labor at the same time. In spite of these conditions, the feeling in general was that most women and couples were not overly concerned or insecure before the delivery. The questions that women and couples ask in the MVC nowadays have changed in character and the questions reflect a common insecurity in connection with the actual delivery.

The aim of this article is to study and reflect upon the experience of midwives in order to use their experience to create a sense of security and provide good nursing care to the expectant parents during their pregnancy and through the delivery of their baby.

\section{METHOD}

When researching this phenomena in the context of living situations in the real world the goal was to detect, analyze and clarify the contents in terms of the issue and the essence of the studied subject. An important aspect of the interviews to be understood with regard to the phenomena of intuition on the part of midwives, was that the subject was discussed and described in explicit and implicit terms $[4,5]$. The interviewer must be skilled and knowledgeable in order to listen carefully to the interviewee to decipher when she is expressing herself in implicit terms. When the implicit content of the interview was clearly understood and clarified we got a more complete picture of the studied phenomena, which was the midwives live world experience of caring for pregnant women throughout their pregnancy term [6].

Phenomenology is a conscious philosophy that is used through language to describe people as subjects of a real world and their experiences as real events $[4,7,8]$. The ancient Greek philosopher Aristotle [9] theorized that thoughts did not exist until one of the senses had experienced it.

\subsection{Data Collection}

The object of the data collection was to compile a database, which reflected and represented the variety and depth of the midwives experiences in working with expectant parents as closely as possible. There were two sources of data included in this study. In order to recruit participants for the study, an interest questionnaire was sent out in the mail to the midwives in the Skaraborg district MVC that is located in the Midwest of Sweden. A verbal presentation was also conducted at a working staff meeting in a delivery ward, in the same area, with the same goal of recruiting participants for the study. The researcher excluded those people who were previous or present colleagues of theirs from being potential participants in the study.

There were eight midwives from the MVC and seven midwives from the delivery clinic who responded that they were interested in participating in the study. Of these, the first ten who responded were chosen to participate in the study. Five of these selected participants were from the MVC and five were from the delivery clinic. The age of the selected interviewees ranged from thirty-seven to sixty-three years old. Their work experience varied in length of time from ten to thirty-seven years.

In order to test the interview guide and verify the interview technique a test interview was carried out under the supervision of an overseer with an eleventh participant. The results of this interview were also used in the study. The interviews of the ten selected participants were performed at each individual's workplace between September and October of the year 2008. The interviews lasted between thirty and sixty minutes each. The questions in the interview guide were as follows:

How do midwives define the concept of security? How do midwives define the concept of good nursing care? What experiences could the midwives recall that created a feeling of security and a good nursing situation? What are the prerequisites for creating security and good nursing care when meeting with the prospective parents? How did the education of the midwives contribute to their ability to create security and good nursing care?

\subsection{Data Analysis}

The above analysis method was performed in four steps [4,6-9]:

The interview material was read through a number of times to get a feeling for the text of the transcripts as a whole and to understand how the phenomena of creating security and good nursing care for expectant parents was accomplished by the midwives.

The interview material was divided into parts where meaning bearing units were identified so that the material was more manageable.

The themes of the interview material were developed from the meaning bearing units. Three central themes were developed:

1) Organizational and Professional prerequisites.

2) The Ability to Communicate on the part of the Midwives.

3) The Reflective and Emotional Competence of the 
Midwives.

The relationship of the concepts from each of the three themes gives us the essence of the interviews. The essence of the interviews reflected how the midwives actually utilized their intuitive inner feelings and how this enables them to provide and create security in order to give good nursing care for the expectant parents.

\subsection{Ethical Aspects}

All of the participants were given oral and written advice regarding the objectives and design of the study. They acknowledged that they were participating of their own free will and all signed a confidentiality statement.

\section{RESULTS}

\subsection{The Function of the Organization and Professional Prerequisites}

The interviewees expressed in their interviews that the knowledge obtained from education is a prerequisite to perform the work of a midwife. The midwives with more experience reported that they have had a lot of exercising and drilling on this sort of practical knowledge and it should enhance their ability to provide security and good nursing care for their patients. The interviewees expressed that the educational element of their training confirmed much of the practical nature of caring for pregnant women up to the point of their delivery. When it came time for the delivery, they felt that they were truly on their own without their mentors to guide them. Newly credentialed midwives are focused on making medical judgments by the manual and reacting to conditions that they perceive to be outside of the normal.

The combination of work experience prior to their midwife education and their experiences of different situations during on the job training was a common thread among the midwives that enabled them to possess the inner confidence to provide the security needed by the expecting couple. This demonstrates that these experiences create something valuable in the midwives intuition that the formal education does not.

Formal education was a catastrophe in the sense that it did little to educate me in group dynamics and psychology... when leading a group of expectant parents one should only be doing and reacting to real life situations without having to consult the manual...in the end I did not feel prepared for this type of situation with regards to my formal training. (Interview \#3)

A large responsibility in preparing the next generation of midwives for their craft is that mentoring midwives bestow upon them their real life experience as well their practical knowledge. In the final phase of a midwives education, a period of twenty weeks is spent on training for the labor phase of the pregnancy and for the actual delivery of the baby in the delivery ward. During this period it is the responsibility of the mentoring midwife to transfer as much of her inner knowledge and experience to the apprentices as possible. This is very demanding on the mentors' energy. This is an important phase in the development of inner security and confidence in apprentices that is such an essential part of being a midwife.

According to the interviewees, the presence and support of their colleagues once they are on their own in the capacity of a midwife is a very important source of knowledge that is both formal and informal. In order to provide good nursing care and create the necessary security in expecting parents it is important to combine the theoretical and practical healthcare knowledge together with the psychological factors involved in order to identify their needs from a holistic perspective. The midwife must appreciate the woman as a unique individual and the woman must understand that what she relates to her midwife will be the basis for determining a specific course of action with regard to her care based on her individual needs. This is an important aspect of the relationship between the midwife and the woman and it is accomplished with the midwife's ability to be competent, keen and sensitive to the woman on an individual basis.

The results of the interviews show that the physical and emotional needs of women in terms of their nursing care vary from woman to woman. Some women desire to have more physical contact in the form of massage and perhaps some demonstration of physical closeness such as an arm around the shoulder or a supporting embrace while others are satisfied to feel at peace with their selves and take some physical presence as needed. In terms of emotional presence, midwives must be informative to the women with regard to their present situation and at the same time be a guide for the future possibilities. The midwife must attentively listen to the couple to decipher what it is exactly that they want to be informed about.

The education of a midwife also consists in coming to an understanding of what the limits of her responsibility are and realizing that there are situations where there is the need for other professional services and caring that she cannot provide. Accessibility to these services and resources can have an important bearing on the course of action in these situations. The interviewees acknowledged that the organization and leadership contribute to the efficiency of how their organization works and they feel that they must be provided with sufficient resources in order to perform their function to the best of their ability. From a perspective of time, they felt that a high 
work load combined with understaffing contributed to the feeling that the midwives could not manage good nursing care for the women. With unreasonable time constraints, the midwife cannot attentively pay attention to the needs of the women.

There are times when there just is not enough time to give the patients what they need...and it is frustrating...I cannot put the blame on myself and therefore I must assign that blame outside of myself and chalk it up to inefficiency within the organization. (Interview \#9)

How work is organized and if the possibility exists for further education and training on behalf of the midwives, has a significant influence on the perception of how work is managed and experienced in the organization. Professional guidance for the midwives combined with an adequate time to reflect upon and discuss the nursing care that is being provided to patients should be the norm of the organization's service as opposed to the exception to the rule.

Through the support of colleagues and with guidance counseling, a midwife gets the opportunity to test their inner feelings about different situations and this enables them to determine their boundaries regarding the responsibilities that they assume as a midwife. Healthcare work can be more effectively organized when the available personnel are utilized as efficiently as possible. For example, assistant nurses and the midwives colleagues are an important part of the organization and they can be effectively utilized in order for the expectant couple to manage their pregnancy and make the delivery as routine as possible. Midwives felt more confident when they had the obstetrician that they trusted the most on duty when they were performing their work. Conversely, when midwives felt they were on a different page than the working obstetrician it would create less than comfortable conditions in certain caring situations. As in any organization, it is very important to have the proper leadership in place so that personnel are in their most effective position and the interviewees were quick to understand this.

...to me it is important who the doctor is that is managing things...and this has an influence on how secure I feel in certain situations...is he listening to what I have to say about my observations with regard to the woman...this is significant about my feelings of security with my patient. Sometimes I am not so confident in the support and I feel as if I am taking too much responsibility in certain situations. (Interview \#6)

\subsection{The Ability to Communicate}

The first meeting between the midwife and the woman or with the couple may well determine how the relationship between the parties will develop. Therefore, it is important to take as much time as needed and to invest some extra energy into this meeting so that the relationship takes root in a positive manner. Midwives need to be attentive and listen carefully to the woman by showing a genuine engagement with them in order to create a trusting and secure relationship.

...I must be into her...it is the personal contact that counts...the eye to eye contact...if there is no connection between us it is going to be difficult if conditions become tough...it won't work. These are basic conditions for effective communication. (Interview \#9)

The ability to communicate also includes the ability to interpret the verbal and nonverbal language. This requires the midwife to listen closely in order to hear what the woman is saying and to understand what is behind her words. In this way, she is studying the woman and learning her mannerisms in order to take what she has to say seriously and responsibly. Body language between the patient and the midwife is significant to the nonverbal communication between the two and it describes information mutually together. The patients are watching the midwife closely as well, to discover the meaning in their body language. To be honest and open in their communication with the couples helps to facilitate the sharing of knowledge and information. This gives both the midwife and the couple the necessary security to encourage the woman to develop and use her own strength and resources.

...but I cannot carry her...the care is about giving her the answers to her questions in order to enable her to take as much control of her situation as possible. (Interview \#3)

Body contact in the form of the examination of the pregnant abdomen through palpitation helps to give the woman a clearer conception of her pregnancy and helps her to identify with the little body within her. The goal of the examination is to help the woman to feel that being pregnant is normal and to clarify and focus on the healthy aspects of it. In this way, it enables the woman to feel secure and create a safe feeling about her pregnant condition.

...I am not afraid to put enough pressure on the pregnant abdomen in order to clarify the position of the baby's body to the mother...I think that is important. The mother becomes more curious about her baby and her abdomen, which is healthy and strengthens them...now it is a baby and not just a big stomach. (Interview \#2)

Midwives should take a position in their conversations with the expectant couples that encourages them to know themselves in order that they pursue their own solutions and make their own decisions. If the expectant parents have the ambition to make themselves knowledgeable and confident enough to make their own decisions it 
gives them a stronger sense of control and a feeling that they can influence their situation. Even in the situation where the midwife has a medical responsibility to react, the goal of the midwife is through communication to encourage the woman and the couple to feel as if they are participating in the decision process.

The man also has an important role in this process and the interviewees noted that a man who felt secure in himself was a source of support that enabled the woman to feel secure. The communication process should encourage the man to participate in all that is happening and occurring. The interviewees observed that it was frustrating when they were not able to reach the couples in their conversations and realized that these couples were the ones who needed the verbal contact. It can be a difficult situation to manage when the communication between the couple does not seem to be working.

...when you have a patient that is not open for any communication at all...it could be a very frightened patient who has just quit on themselves...I think that is difficult...maybe the couple is not even communicating with each other...this is not easy. (Interview \#4)

The interviewees felt that the well prepared parents were the ones that were communicating well with each other, as well as communicating effectively with the midwife. They felt that this made the nursing care more managable and enabled the midwife to not feel alone when the couple was participating in the process of creating a positive experience of both the pregnancy and the childbirth. It appeared to the interviewees that the number of women who were lacking in confidence to manage their own birth of their child was increasing. A consequence of this lack of confidence in women is that they feel more afraid and insecure, which makes it more difficult for the midwife to create an atmosphere of security.

\subsection{The Reflective-Emotional Competence}

The reflective-emotional competence is the experience based silent knowledge that is acquired after working in a field such as midwifery for a long period of time. This knowledge enables a midwife to see each expectant couple as a unique set of circumstances and actually feel their emotional, physical and spiritual needs. From this knowledge, the midwife is able to create an overall vision for their expectations and design an environment that will provide both security and good overall nursing care. This vision should create a sense of teamwork between all of the parties with the midwife using herself as a tool and taking the responsibility to establish the roles of all those participating. One interviewee describes that when she feels the sensation of establishing the prerequisite chemistry for the situation, she views this as an invitation from the couple and this gives her an emo- tional confidence to securely manage their pregnancy and delivery. The midwife must get herself in a position where she has a definite feeling about where the couple is in their emotional state before she can provide the total nursing care strategy required for the delivery of the baby.

...I don't come into a situation with all of the solutions in my pocket...first, I must land in their situation and observe all of the necessary details and make order of it...where are they in their emotions and feelings? For example...I think this is what creates security for them... if it is not anything urgent I recommend that there is nothing to be in a great hurry for... this usually gives them the confidence to relax fairly quickly. (Interview \#9)

When the woman is in the actual labor phase of her pregnancy, she is hypersensitive to everything that is going on in the room around her. She is acutely aware of both her partner and the midwife and about their emotional state without verbal communication. The midwife has been studying the couple throughout the pregnancy and enabling them to develop their own set of resources. She is aware of if the couple is in need of extra support and at the same time she is ready to provide that support in order to create the necessary level of security that the situation demands. When she does this, she is fulfilling her obligation to provide good nursing care to them. To have a special love for people and to have a love and passion for her job is a real motivating force for the midwife to create this bond between all of those participating in the pregnancy. This gives the couple a positive experience in connection with their child bearing.

...ah yes...I had a couple who...in other words I think it is really funny with first time parents...when I took over it seemed really tough and the decision had been made for a Caesarean section...and then I felt just that...no!...now we shall continue...work on...and the father became such a pillar of strength, who so strongly took on his role supernaturally...positively...and coached her...we can do this!...so, I just pulled a bit and stayed out of the way... when I saw what I saw I just encouraged them to keep working and got her to deliver on her knees...she was able to take out the baby on her own...ahhh...the three of them became one...baby, mother, father...I thought about doing the navel string test but then I thought to myself forget about doing that...it was such a long delivery, a first born at that...it felt like such a victory... with such a simple remedy, by encouraging them it accomplished everything...it went so well...oh yes...happiness!...what a feeling!...it made me shiver...they had so much strength in themselves...they amazed me...I did that and I didn't really do all that much...but it got them to do it for themselves...in the end, it makes me wonder about what it is 
that a couple needs from the midwife and perhaps perform some sort of analysis...it seems that this couple needed maturity and insight from me. (Interview \#7)

Midwives develop much of their nursing care strategy for the women and the couple on the basis of their individual emotional and psychosocial needs instead of purely on the basis of the usual and customary controls and procedures that are mandated by the ministry of health. Midwives manage the balance of purely medical standpoints and the other practical aspects of healthcare proceedings based on individual needs. These practical aspects may include simple things such as encouraging someone to join a prospective parent group, an appointment with a psychologist or perhaps encouraging contact that is more frequent with the midwife. Interviewees felt that the reflective and emotional counseling throughout the pregnancy and up to the delivery was the more time demanding and complicated aspect of the midwives duties. One interviewee describes both the hard and the soft variables. The hard variables are the ones that are measurable such as blood pressure, external measurements such as the size of the abdomen, the baby's heartbeat and other routine tests. The soft variables are the woman's emotional wellbeing and her ability to manage her pregnancy. Often an appointment with the midwife is a routine meeting in the beginning with respect to the hard variables. Dealing with the soft variables was more complicated because the emotional issues seemed to come up at the conclusion of the meeting, which could lead to exceeding the time constraints.

...I usually begin with the controlled measurements immediately...many of the women come with their concerns and questions at the end of the meeting...they do not seem to be comfortable taking them up directly at the beginning of the meeting...I need to read the women better. (Interview \#11)

According to the interviewees, the midwives need to feel secure in order that they convey their security to the women and the couples. This creates a secure atmosphere, which enables both security and good healthcare to be established. One midwife explained in her interview that one of her professors in the midwife education said that the number one contradiction in the actual delivery itself was to have an emotionally incompetent midwife in the delivery room. This served as a reminder to this midwife, that even in situations where she would feel stress levels growing in her, it was absolutely necessary to remain outwardly calm and in control of herself in order to not alarm her patient.

\subsection{The Essence}

The participants in the interviews, generally speaking, acknowledged that they had learned to trust and depend upon their inner feeling and intuition in their work as midwives. Using this intuition as an important tool and motivating force in their craft enabled them to trust themselves and their competence in order to analyze a situation, make a decision and formulate a solution. Even with their abundance of experience, the interviewees still feel a fascination and awe with this feeling of intuition as it enables them to know what every parent and couple feels and what they need to know with regard to their experience of their pregnancy and delivery. They relate that in most cases their inner feelings and intuition were confirmed in the successful delivery of the baby. The more experienced midwives felt that their reliance upon this inner knowledge was directly proportional to their level of experience and they believe that the more experience they received, the more they trusted their intuition to help them make important decisions in the birthing of babies. The midwives expressed a deep sense of satisfaction when their colleagues gave their approval and acknowledged their intuition during a situation but at the same time, they felt that it was frustrating when the same colleagues did not share their intuition in other situations. The sense of intuitive knowing also enables the midwives to combine all of their theoretical knowledge with their practical experience that they have accumulated over the years, which gives them a more complete and comprehensive knowledge system to handle all of the possible situations and outcomes related to pregnancy and delivery.

\section{DISCUSSION}

All of the interviewees described this sense of intuitive knowledge and it ran like a red thread through all of the themes that they discussed. The interviewees pointed out that the level of this intuitive knowledge and the ability to use it in a given situation was directly proportional to the level of their experience. It stands to reason that the more healthcare situations that a midwife had participated in, the more experienced she was in the possible outcomes to any given situation which enabled her to use her intuition in order to give the women and couples a sense of security in delivering their babies. Intuitive knowledge was found to be a valuable tool to be used in acute and emergency situations as well as those situations that were not of an emergency nature. Olafsdottir [10] describes in her dissertation how midwives use this intuition on a deeper level, as if there is a sixth sense, to care for their mothers to be. Berg, Lundgren, Hermansson and Wahlberg [11] describe this sixth sense as a reciprocal communicative process between the midwife and the parents to be. They describe the phenomena of the mothers anticipating the midwives thoughts and actions from their perspective without the 
spoken word.

According to the Educational Reference Book [13] the word intuition means to have an immediate understanding about a thing or condition without logical grounds in fact. When healthcare workers work for a number of years and acquire the necessary experience they find themselves confident enough to make crucial decisions that they cannot explain afterwards, but upon later inspection find themselves to be entirely correct. This phenomenon is further confirmed by Benners theory [14] about the different levels of apprenticeship that the nurse goes through, from the novice to the highest level of healthcare related skills that consist of intuitive understanding of every situation and the ability to act immediately with skill and confidence.

This brings us to the question as to whether intuition can be taught. Young [15] found in their study that intuitive feeling cannot be taught without actually having the experiences necessary to provoke these feelings. She found that nurses can, however, be trained to know their own subjective facts and to make their decisions based upon this knowledge. Rew [16] concludes that students can develop their intuition through different practical experiences. From an organizational perspective contributions to the development of an individual's intuitive ability to know things may be the result of management organizing the work so that more experienced midwives are able to share their experience with less experienced workers.

When communicating with the women and the couples, the midwives are using themselves as a tool to build a confidential relationship with the parents to be. Since the midwives are also being observed from the perspective of the women and the couples, their body language must confirm to them that the information given to them is trustworthy and reliable. Interviewees feel that their value to the expectant mothers and couples is to give them a sense of confidence in themselves and to help them develop a positive attitude about the birth and delivery of their baby. They felt that an important factor in this development was their ability to communicate by giving and receiving information with competence. When the interviewees had difficulty in establishing a good communication with their expectant couples, they found that both parties were in turn frustrated by this and this was confirmed in studies by Halldorsdottir [17], Nilsson, and Waldermarsson [18]. Consequently, the interviewees felt that it would be very helpful to receive more education in the area of communication skills. Education in motivation interview technique is a high priority for these midwives in order to motivate the women and couples to help contribute to their own solutions and caring according to Barth and Näsholm [19].
Practical knowledge and many experiences contribute to the foundation of the ability of the midwife to see each expectant mother and couple as a unique set of circumstances on an individual basis. The midwives describe their engagement with the women and couples as an emotional interplay that requires keen listening skills regarding the expectant parent's needs. There is a reciprocal nature in the relationship between the midwife and the women as well, because when the midwife feels secure in herself this feeling of security is transferred and has a calming effect on the woman. According to Norberg [20], healthcare philosophy comes from a Christian Humanist point of view. She maintains that healthcare management can create an artwork that expresses an attitude about life and this attitude can reflect a deeper engagement in healthcare philosophy.

The interviewees express in the study that the meeting with the prospective parents is not just about their formal competence and practical skill. The meeting is largely about their attitudes and feelings regarding people, in combination together with their moral and ethical makeup. The midwife profession demands a special love for people in order that they can feel secure in emotionally engaging with them on a matter that is so important as childbearing. According to Benner [21], the ability to be emotionally competent and to listen keenly to your patient cannot be a forced ability, but it must come from within if one is truly an expert in the area of healthcare. In other words, one must have a personal presence.

I have reached the conclusion that as nurses and midwives, we have an enormous power to influence how people experience their very first and their last hours of their lives. As midwives, we routinely encounter women in different situations who are in a position of weakness, therefore it is imperative that we are conscious as professionals of this power and how we apply it in their care. During the course of my twenty years as a midwife, I have been present to many conversations and discussions with prospective parents that spoke of their experiences surrounding their pregnancies and childbearing. They seem to be, overall, content and satisfied with their experiences. When the midwife shares in their happiness or sadness it strengthens their experience and gives them warmth, a feeling of security and even an inner strength that they carry with them further in their lives. It seems that when their experience is not perceived in a positive manner it is often dependent on the failure of the midwife to create a relationship that is based on her ability to communicate and establish the couple in security and confidence. This can create an unbalance in the perception of control of the couple's destiny in their prospective childbearing. This provokes the question as to how can we conduct this relationship 
between our expectant parents so that we can reach the goal of a positive experience of the pregnancy, delivery and the child's birth to all couples.

\section{Further Research}

According to Benner's [21], nurses and healthcare personnel go from the novice to the expert in their field of work through an accumulation of experience that they attain from their work experience. One question that comes to mind is how the organization can adjust the management of the workload in the system to the level of the cumulative experience of the staff. How can the experience related inner knowledge that leads to intuition, be effectively transferred to new personnel? How can the organization and the education process best utilize the expert knowledge of the more experienced midwives? Finally, we might ask, how can the intuition and inner knowledge of the most experienced midwives be utilized in the education of the expectant parents? Can we use this inner knowledge to further develop and improve the parent groups that focus on the ability and the strength of the parents to contribute to a more positive experience in the pregnancy and delivery of their child?

\section{CONCLUSIONS}

If intuition is a difficult concept to define or understand, perhaps it is even more difficult to measure the effects of its use in midwives' working to create security and good nursing care with expecting parents. The interviewees in the study discussed how their inner feelings motivated them in their work. For midwives to feel that they can perform their work in a satisfactory manner, the nursing care profession and the healthcare organization must provide them with a secure workplace and environment. According to the interviewees, expectant parents want and expect the security that goes with competent nursing care, in order that they will feel confirmation and respect in the treatment that they receive. Their feelings regarding their security and treatment were largely dependent upon the emotional engagement that was created between the midwife and the couple.

Expecting parents are often meeting with midwives in their first major change of life period within the healthcare network. Since many times these couples are relatively young and inexperienced, they are dependent on the midwife to be competent and have rather well developed communication skills. This is why it is so important that these skills are emphasized and are a focus of the midwife's development and education. A practiceing midwife is expected to be able to make difficult decisions in different healthcare situations. The support of colleagues and their counsel helps to encourage an engaged relationship between the midwife and the expec- tant parents. There are going to be times when a midwife will be required to manage difficult emotions on the part of the expecting parents, such as suffering and grief and this is when the support of their colleagues is so important. It helps the midwife to manage their own emotional stress in order that they can remain open and flexible during difficult circumstances.

\section{REFERENCES}

[1] Hildingsson, I. and Häggström, T. (1999) Midwives' lived experience of being supportive to prospective mothers/parents during pregnancy. Midwifery, 15, 82-91. doi:10.1016/S0266-6138(99)90003-7

[2] Lundgren, I. (2004) Releasing and relieving encounters: experiences of pregnancy and childbirth. Scandinavian. Journal Caring Science, 18, 368-375. doi:10.1111/j.1471-6712.2004.00300.x

[3] Fischer, C., Hauck, Y. and Fenwick, J. (2006) How social context impacts on womens fears of childbirth: A Western Australian example. Social Science \& Medicine, 63, 64-75. doi:10.1016/j.socscimed.2005.11.065

[4] Giorgi, A. (1997) The theory, practice and evaluation of the phenomenological method as a qualitative research procedure. Journal of Phenomenological Psychology, 28, 235-260. doi:10.1163/156916297X00103

[5] Söderlund, M. (2003) Tre kvalitativa forskningsansatser med relevans för vårdvetenskap. Vård i Norden, 23, 9-15.

[6] Dahlberg, K. (1997) Kvalitativa metoder för vårdvetare. Studentlitteratur, Lund.

[7] Englander, M. and Robinson, P. (2008) Appliceringen av den deskriptiva fenomenologiska humanvetenskapliga metoden. Vård i Norden, 28, 49-51.

[8] Englander, M. and Robinson, P. (2007) Den deskriptiva fenomenologiska metoden. Vård i Norden, 27, 57-59.

[9] Stensmo, C. (1994) Pedagogisk filosofi. Studentlitteratur, Lund.

[10] Swanson, K.M. and Wojnar, D.M. (2007) Phenomenology: An exploration. Journal of Holistic Nursing. 25, 172- 180. doi:10.1177/0898010106295172

[11] Olafsdottir, O.A. (2006) An icelandic midwifery saga, coming to light, with woman and connective ways of knowing. Ph.D. Thesis, Thames Valley University, Reykjavik Island.

[12] Berg, M., Lundgren, I., Hermansson, E. and Wahlberg, V. (1996) Women's experience of the encounter with the midwife during childbirth. Midwifery, 12, 11-15. doi:10.1016/S0266-6138(96)90033-9

[13] Educational Reference Book (Pedagogisk Uppslagsbok) (1996) Från A till Ö utan pekpinnar. Fälts tryckeri, Värnamo.

[14] Benner, P. (1993) Från novis till expert - mästerskap och talang i omvårdnadsarbetet. Studentlitteratur, Lund.

[15] Young, C.E. (1987) Intuition and the nursing process. Holistic Nursing Practise, 1, 55-62.

[16] Rew, L. (1990) Intuition in critical care nursing practise. Dimensions of Critical Care Nursing, 9, 30-37. doi:10.1097/00003465-199001000-00011

[17] Halldorsdottir, S. and Karlsdottir, S. (1996) Empowerment or discouragement: women's experience of caring 
and uncaring encounters during childbirth. Health Care for Women International, 17, 361-379.

doi:10.1080/07399339609516251

[18] Nilsson, B. and Waldemarsson, A.-K. (1995) Kommunikation. Samspel mellan människor. Studentlitteratur, Lund.

[19] Barth, T. and Näsholm, C. (2006) Motiverande samtal -
MI. Att hjälpa en människa tillförändring på sina egna villkor. Studentlitteratur, Lund.

[20] Norberg, A. and Nilsson, K. (1997) Omvårdnadens mosaik: En modell. Liber, Göteborg.

[21] Benner, P., Tanner, C. and Chesla, C. (1999) Expertkunnande i omvårdnad, omsorg, kliniskbedömning och etik. Studentlitteratur, Lund. 